\title{
DEFINING SYSTEMS OF INNOVATION: A METHODOLOGICAL DISCUSSION ${ }^{1}$
}

\author{
Slavo Radosevic
}

\begin{abstract}
The current definitions of systems of innovation (SI), which define SI in institutional terms only, do not resolve the key bottleneck in conceptualising this notion. The paper develops a conceptual framework which enables more structured understanding of SI based on four building blocks: technological regime, institutional set-up and market and pre-market selection environments. This allows SI to be defined as a co-evolution of technological regimes and institutional set up moulded through mechanisms of market and pre-market selection.
\end{abstract}

\footnotetext{
${ }^{1}$ This paper is one of the outcomes of my participation within the international research network on systems of innovation. Discussion on 3 workshops in Vadstena and Soderkoping (Sweden) and Lanzarote (Canary Islands), based on the chapters of the forthcoming book (Edquist et al), contributed to much of my thinking on these issues. I am highly indebted to the members of the research network for stimulating discussions.
} 


\section{Introduction}

Systems of innovation (SI) has become a widely accepted concept in innovation studies for two reasons. First, it is an attempt to go beyond R\&D in explaining innovation dynamics. The SI concept assumes that the rate of technical change does not depend only on the scale of different countries' R\&D but also on inter-organisational learning processes. Second, these processes are very much influenced by the institutional set-ups which foster competition and co-ordination. The notion does not encompass only stock of knowledge (R\&D stock or technology capital) but also institutional elements which are strongly influencing growth dynamics. This is an important potential advantage of the SI perspective, especially in relation to new growth theory where flow is just a time derivative of stock of knowledge. SI should potentially better explain how technical opportunities convert into economic growth.

While being a promising line of research it seems that at the same time this research program entered into a phase of diminishing returns, at least temporarily. Empirical research done under this heading has not resulted in more theoretical insights while theoretical research seems to have got stacked into the all encompassing notion of institutions. Two problems in particular seem to indicate this state, first, the problem of systems boundaries, and second, an enormous institutional diversity of SI.

\section{Boundaries of SI}

Even from the very beginning of research in this area there were strong reservations regarding the boundaries, particularly national, of $\mathrm{SI}^{2}$. Especially the notion of NSI is a loose one and not sufficiently specified. Carlsson and Stankiewicz (1993) introduced the notion of technological system (TS) which imply that the boundaries of TS are indeterminate, meaning that these systems could be local, global or national. Indeed, a current agreement seems to be that systems boundaries are indeterminate (see Edquist et al, forthcoming). However, this has not solved the problem of what determines system boundaries.

\footnotetext{
${ }^{2}$ See Nelson (1993) and Lundvall (1992) introductory chapters.
} 


\section{Institutional variety}

The second problem in understanding SI is that it is defined only in institutional terms. (See an overview of seven definitions in the footnotes 3 and 4$)^{3}$. Even the definitions of technological system (Carlsson and Stankiewicz, 1991), and sectoral SI (Breschi and Malerba, 1995), which should have a clear reference to the specific characteristics of different TS or TR are also defined only in institutional terms ${ }^{4}$.

This highlighta two problems: first, what are institutions and, second, which institutions are relevant in explaining SI. In this paper we will leave aside the first problem as it would further complicate our main argument. However, the second problem, which institutions do matter for SI, should be discussed as it tackles the problem of definition of SI.

A solution for resolving an enormous institutional complexity has been solved so far by the opportunistic strategy of sticking mainly to the notion of organisations (enterprises, universities, other R\&D institutions) and avoiding

\footnotetext{
${ }^{3}$ Freeman (1987), who first coined the term NSI, defines it as: the network of institutions in the public and private sectors whose activities and interactions initiate, import, modify and diffuse new technologies may be described as the 'national system of innovation.
}

Nelson (1993) does not have one clear cut definition of NSI. (NSI is) a set of institutional actors that, together, plays the major role in influencing innovative performance. (This is)not limited to (...) firms at the forefront of world's technology, or to institutions doing the most advanced scientific research (but on) the factors influencing national technological capabilities. .... (Thus, there is) no sharp guide to just what should be included in the innovation system, and what can be left out.

Niosi et al (1993) define NSI as the system of interacting private and public firms (either large or small), universities, and government agencies aiming at the production if $S \& T$ within national borders. Interaction among these units may be technical, commercial, legal, social, and financial, inasmuch as the goal of the interaction is the development, protection, financing, or regulation of new $S \& T$. (p. 212)

Lundvall et al (1992) make a distinction between a SI in the narrow sense and a SI in the broad sense. The narrow definition would include organisations and institutions involved in searching and exploring - such as $R \& D$ departments, technological institutes and universities. The broad definition (...) includes all parts and aspects of the economic structure and the institutional set-up affecting learning as well as searching and exploring - the production system, the marketing system and the system of finance present themselves as sub-system in which learning takes place (p.2).

Patel and Pavitt (1994, p. 79) define NSI as the national institutions, their incentives structures and their competencies, that determine the rate and direction of technological learning (or the volume and composition of change-generating activities) in a country.

${ }^{4}$ Carlsson and Stankiewicz (1991) define technological system (as) a network of agents interacting in the economic and industrial area under a particular institutional infrastructure and involved in the generation, diffusion, and utilisation of technology. Malerba and Breschi (1995) define sectoral systems of innovation (...) as the population of firms which are active in the innovative activities of a sector. Such firms are engaged in the generation and utilisation of new technologies and they are involved in process of interaction, co-operation, competition and selection. (p.1) 
analysis of other types of institutions (legal, informal, patterns of behaviour). However, even from this perspective the institutional complexity of NSI is still analytically unmanageable (see Nelson, 1993). Without a common conceptual framework presentations of SI are never exhaustive as 15 case studies in Nelson (1993) show. As a result there is always temptation to add additional factors which could further explain the system not does adding more countries in descriptive analysis solve the problem.

Based on such understanding of the problem we try to develop here a conceptual framework for defining SI which might hopefully resolve some of the vagueness of the concept.

\section{Basic building blocks}

The basic building blocks of our SI framework are shaped by the structuring forces and mechanisms of selection. Structuring forces are technological regime and institutional set-up. Mechanisms of selection, which ensure the dynamics of SI, are pre-market and market selection mechanisms.

\section{Technological regime (TR)}

TR as a concept is developed by Malerba and Breschi (1995). TR is defined by the level and type of opportunity and appropriability conditions, by the cumulativeness of technological knowledge and by the nature of knowledge and the means of knowledge transmission and communications (p. 3). TR is basically a technological trajectory but defined multidimensionally. (See table below).

Relevant dimensions of technological regimes (TR)

\begin{tabular}{|l|l|l|l|}
\hline Opportunity & Appropriability & Cumulativeness & Knowledge Base \\
\hline Level & Level & Technology & Generic/Specific \\
\hline Pervasiveness & Means & Firm & Tacit/Codified \\
\hline Variety & & Sector & Simple/Complex \\
\hline Source & & Area & Independent/System \\
\hline
\end{tabular}

Source: Breschi and Malerba (1995) 
Different dimensions of TRs are basically sub-building blocks by whose recombination is possible to get different sectoral SI whose boundaries are determinate ${ }^{5}$.

Specific properties of TRs crucially affect the organisation of innovative activities and the dynamics in the population of innovators across different sectors. In that respect they set the boundaries of institutional diversity. For example, it would be impossible that the car industry today could be developed in hundreds of small shops as happened at the beginning of this century. Current TR of this sector puts clear boundaries to institutional diversity in organising its innovative activities.

An objection to the notion of TR is that it abstracts from institutional set up Opportunities, appropriabilities, cumulativeness and knowledge base do not come as manna from heaven but are themselves the product of institutional development also. The answer is that institutions are embedded to some extent in the very notion of TR (Malerba and Breschi, 1995, p. 4) to a degree that they are now 'hard' facts and hence can be characterised as technological. However, that does not solve the problem of institutional differences based on the same TR. The same sector can be organised in different countries in different ways and yet be very similar in terms of TR dimensions. Whether these institutional differences are then relevant or not will be discussed later. The point is that the notion of SI has not only to have explicit reference to TR but also to institutions.

\section{Institutional set-up}

The core idea behind the SI research program is that differences in national or sectoral institutional set-ups, i.e. the way countries or sectors organise their innovative activities matter. Among NSI institutional differences are (Lundvall, 1992) in the internal organisation of firms; interfirm relationships; the role of the public sector; the institutional set-up of the financial sector; and R\&D intensity and R\&D organisation. Descriptive studies of different NSI show a huge variety of institutional landscapes such that it is very difficult to decide which institutional

\footnotetext{
${ }^{5}$ On this basis Malerba and Breschi (1995) distinguish five patterns or sectoral SI:

1. Traditional sectors such as shoes and textiles: many innovators, geographically dispersed with no specific knowledge spatial boundaries

2. Mechanical industries and the industrial district: many innovators, geographically concentrated with local knowledge boundaries

3. The car industry: few innovators, geographically concentrated with local knowledge boundaries

4. The computer mainframe industry: few innovators, geographically concentrated with (internal) and global knowledge boundaries

5. Software, the modern electronics industry and Silicon Valley: many innovators, geographically concentrated with both local and global knowledge boundaries.
} 
differences are 'noise' and which are relevant or explanatory. Institutional development cannot be understood outside specific historical and country or sector contexts, which poses huge problems for comparative work. Indeed, our understanding of the role of institutional set up in innovation dynamics significantly improves when the whole context of path dependency or historical origin, functions and built in incentives are taken into account. We may temporarily conclude that the historical institutional analysis is the most appropriate way to analyse the link between institutional set up and innovation dynamics.

However, firstly, historical institutional analysis has low predictive power, and, secondly, it is very difficult to generate much theoretical insight from it as specificity of particular historical moment is often not transferable to other contexts. Obviously we need greater theoretical understanding of how institutional set ups influence innovation dynamics.

The task is to link particular institutional structures to paths of technological development or to understand which technology patterns can be accounted for by institutional variations. As Zysman (1993) rightly points out the notion of SI should specify how the 'system' drives innovation trajectories ${ }^{6}$. On the other hand innovation trajectories are not entirely plastic, i.e. shaped by the institutional setups. They are structured significantly by the current levels of S\&T which subsequently shape institutional set-ups. The complexity of SI as a notion arises from an interplay of technological trajectories and institutional set ups. Institutions define the SI but only through their co-evolution with technological trajectories and TR.

By now we have two building blocks of our framework, TR and institutional set-up. Basically they are not something new in the area of innovation theories (See Rosenberg, 1976, 1982; Freeman and and Perez, 1988). What is new is the notion of technological regimes which enables us to be more specific in conceptualising the link between technology and institutional set up as structuring forces of SI. Premarket and market selection mechanisms are the two following elements which give dynamics to our framework.

\footnotetext{
${ }^{6}$ Zysman (1993) himself finds the way out in 'historical institutional analytical strategy' of research. We find this approach very costly and with low theoretical value. While it generates a wealth of insights at the same time it requires voluminous descriptive analysis and it has low theoretical value.
} 


\section{Pre-market selection}

Pre-market selection mechanisms operate chiefly within the firm (like business strategy) and within the bureaucratic and legal structures (e.g. R\&D funding, patent laws) ${ }^{7}$. In the creation of SI processes of pre-market selection are very important as the cases analysed in Carlsson and Jacobsson (1995) confirm. However, SI are ultimately shaped through an interplay of pre-market and market selection mechanisms. They are mixtures of public and private actors whose joint interaction might produce either coherent or fragile institutional constellations.

\section{Market selection}

Market selection is the ultimate criterion of viability of new technologies. While pre-market selection generates much higher technological variety the market selection reproduces only economically relevant variety which is narrower in scope.

These four building blocks constitute our conceptual model of SI. The proposition is that SIs are constituted through coupling between TRs and institutional set-ups where different selection environments give dynamics to the system. How these four building blocks are interrelated can be seen from the table below.

\footnotetext{
${ }^{7} \mathrm{New}$ technologies, especially simulation modelling and techniques, have moved the boundaries of pre-market selection much more inside the firm, due to the spread of virtual experimentation and simulation techniques which avoid costs of trial and errors through market experimentation (Stankiewicz, 1995).
} 
Structuring forces of Innovation Systems and mechanisms of selections

\begin{tabular}{|c|c|c|}
\hline Field IV & $\begin{array}{c}\text { Pre-market } \\
\text { selection } \\
\text { (intra-firm procedures, } \\
\text { patents, R\&D funding) }\end{array}$ & Field I \\
\hline $\begin{array}{c}\text { Technological regime as } \\
\text { a structuring force }\end{array}$ & & $\begin{array}{c}\text { Institutional set-up as a } \\
\text { structuring force } \\
\end{array}$ \\
\hline Field III & $\begin{array}{c}\text { Market selection } \\
\text { mechanisms } \\
\text { (price, demand, market } \\
\text { power) }\end{array}$ & Field II \\
\hline
\end{tabular}

While elements of our framework do not by themselves seem to be anything new their mutual relationships offer interesting insights for a more theoretical understanding of the SI concept. Two structuring forces and two mechanisms of selection produce four fields of interaction. These four fields represent different aspects of SI. While both structuring forces and mechanisms of selection are present in all SI different systems are skewed towards different fields. Mutual interaction in four factors of our framework is enough general to encompass different configurations of SI.

\section{Field I: Forms of knowledge products are plastic}

In this field institutional set up gives boundaries of pre-market selection while pre-market selection may modify institutional set up. For example current funding institutions and their rules limit the possibilities for changing priorities. A weak patent system rooted in corresponding laws and institutions for monitoring property rights will not stimulate firms to search for patentable products. On the other hand very strong and priority driven funding will gradually create an entirely new institutional landscape which will eventually lead to new bunch of R\&D results to be later tested through market selection. Tight patent laws which will eventually be supported by an institutional set up (a patent office, patent centres) will lead to more patenting of innovations. 
The point is that different institutional characteristics, like the degree of codification, completeness of disclosure, ownership status, play a crucial role in shaping the character of R\&D (knowledge products) (David and Foray, 1995) ${ }^{8}$. The main proposition developed by David and Foray $(1994,1995)$ is that these, basically institutional characteristics, are not inherent in the knowledge itself but are the product of social organisation and of the attendant reward structures of those institutions supporting the production of knowledge. As a result, knowledge products are very plastic, i.e. they are to a significant extent shaped by the social characteristics of knowledge production ${ }^{9}$. Although Foray (1995) puts reservations on this strong proposition it well illustrates the basic perspective ${ }^{10}$.

From the perspective of our framework we put strong reservations on how general is this aspect of SI. While it can quite well be applied to the science and $\mathrm{R} \& \mathrm{D}$ spheres, i.e. to areas where pre-market selection is the dominant selection mechanism it is not applicable to the classes of SI where market selection is the dominant mechanism. Indeed, many of examples that David and Foray exploit to support their proposition on the institutional plasticity of knowledge products are from science and not from the technology area.

\section{Field II: Organisational regime as a criteria of market selection}

In this field institutional set up gives criteria and thus boundaries for market selection while market selection represents the main test for (mis)matching or viability of different enterprise and inter enterprise institutional arrangements. For example, network type of firms is seen as conducive for sectors with flexible specialisation production regimes. Those countries that are unable to develop such

\footnotetext{
${ }^{8}$ Any knowledge product could be positioned with respect to these (three) four dimensions. ${ }^{9}$ This basic proposition enabled David and Foray (1995) to develop the proposition that systems that strongly support distribution of knowledge and which are thus based on a rather different set of incentive structures have distinctively different innovative dynamics and patterns. The flow of knowledge in 'knowledge distribution oriented systems' generates opportunities for innovation. Hence it is not only the flow of innovation which generates knowledge but also the system which fosters knowledge distribution or exchange. Although extremely interesting this proposition is beyond our concerns here.

${ }^{10}$ Foray (1995) puts it this way: However, there is not any exact, deterministic association between a given institutional context for research activities and the form that a knowledge-product will take. Rather, institutions and organisations, and the norms governing the actions of their members, possess a measure of elasticity, or 'suppleness', that permits the knowledge-products that they cater for to be expressed in some range of forms - scientific papers in professional journals, patents, presentations at open conferences, shared expertise, confidential memoranda - depending upon the range of incentives and institutional compromises among conflicting goals. (p. 5)
} 
organisational forms are supposed to lag in terms of dynamic growth. The basic idea, which is in the context of SI developed and tested by Guerrieri and Tylecote (1995), is that there are some fundamental behavioural requirements for successful innovation and for dynamic SI ${ }^{11}$. Specific organisational dimensions of the system (firm organisation and its relations with infrastructure) are the main criteria of market selection. It is the robust organisational regime around which market selection evolves. Market selection rejects those SI whose organisational regime does not match the specific robust institutional set up conducive to innovation dynamics. Much of the managerial literature is based on an implicit claim that it is able to recognise those organisational systems which are able to assimilate technological change and withstand market selection.

The spread of Japanese management techniques around the globe shows that an organisational regime like Toyotism has wider inter-industry applicability. Matching of a specific country's organisational styles to this 'robust design' serve as a criterion of market selection.

\section{Field III: Technological regime as a criteria of market selection}

In this field technological regime is formed and it represents the main criteria for market selection. Enterprises and related networks (in other words, SI) which do not fit with the dominant characteristics of TR have low chances of survival. TR, through technological opportunities, appropriability regime, level of cumulativeness and the character of knowledge base, determine the shape of SI, including its spatial boundaries. Analyses of relevant dimensions of TR find strong similarities across countries in the ranking of sectors according to various measures of TR (particularly for opportunity and appropriability) even though in absolute terms sectors differ from one country to another with respect to the same measures (Malerba and Orsenigo, 1990; Breschi and Malerba, 1995).

\footnotetext{
${ }^{11}$ In the particular case behavioural requirements for technological advantage are dominantly micro (enterprise level). These are: functional (among the different functions and departments within the firm), vertical (up and down of command and among the different levels of management), and external (with other organisations). Beside these there are external requirements for technological advantage (science base, technically-trained manpower, financial system). On that basis trade and technological (patents) performance of countries can be explained by the degree of 'fit' between the 'behaviour' and 'external' requirements of specific industries and 'sub-families', and the extent to which countries meet these requirements (Guerrieri and Tylecote, 1995).
} 
TR imply that technological imperatives are strong and determining factors for market selection. However, further more detailed empirical work would probably show differences in TRs in the same sectors across different countries ${ }^{12}$.

This field neglects areas where pre-market selection is the dominant selection mechanism which opens possibilities for different organisational arrangements. However, this field is highly relevant for many SIs and especially those where technology is largely embodied in hardware or is standardised.

\section{Field IV: Pre-market selection as a modifier or generator of TR/ TR and boundaries of pre-market selection}

Current technological regimes (TR) determine boundaries of pre-market selection. For example, public R\&D funding priorities (pre-market selection) are to a great extent determined by $R \& D$ areas of enterprises which are mainly within the current technological trajectories and TRs. On the other hand, pre-market selection may change technological regime or create new ones, as in the case of many military related technological areas. A good example of this is the nuclear industry, which was a spin-off from military programs and has reached the level where one can talk about specific nuclear industry SI with their very specific technological regime.

Whether pre-market selection mechanisms can create new technological trajectories and TRs is to a great extent determined by the prevailing socioinstitutional context. For example, pre-market selection mechanisms are not strong enough to create push in the direction of faster technological development of a welfare complex, as opposed to military complex, which then might create distinctively new TRs.

At pre-market selection level institutional set up is much more important as a selection mechanism. Pre-market selection can strongly influence TR and, thus, to a great extent shape the market selection process. For example, national security concerns are very powerful pre-market selection mechanism (Nelson, 1993).

\footnotetext{
${ }^{12} \mathrm{Big}$ methodological problems are caused by the unavailability of patent and other data at subsectoral levels. The assumption that TR work at the desegregation level of 50 technological classes, which is the level used in the Malerba et al papers, is more a convenience caused by the lack of data than a theoretical proposition.
} 


\section{Corollaries}

From this framework four corollaries follow:

Corr 1. SI should be defined not only in institutional terms but also in technological terms or more specifically in terms of technological regimes. Our basic proposition is it is the coevolution of institutions and technological regimes which gives coherence and dynamics to SI.

Corr 2. TR is a structuring force which provides boundaries of institutional diversity. Only those institutional differences which influence and shape TR are relevant from an SI perspective.

This (at least theoretically, if not practically) solves the problem of institutional noise (irrelevant institutional diversity) and compensatory institutions ${ }^{13}$. In that context the notion of NSI is methodologically sound only if we are able to show that different TRs within a country contain certain common traits. For example, we would have to show that TRs across Danish niche productions, which are most often in slow growth industries, have some common traits which represent distinct national meta-technological regime ${ }^{14}$.

Corr 3. Institutional set up may influence TRs and organisational regimes. This is especially true in the pre-market selection phase where institutions play a much more important role in the dynamics of some SI (fields I and IV).

The discussion on variety within the SI context still suffers from vagueness and it still does not clearly address the problem - variety of what? Outputs, technologies, institutional forms? How these varieties relate to each other? Our framework enables us to distinguish between variety induced by pre-market or market selection mechanisms as well as between variety in organisational regimes vs. variety in

\footnotetext{
${ }^{13}$ By this we mean that many institutional forms can be used to perform basically the same or similar functions and the same functions can be performed in different ways in different SIs. For example, risk capital was in the 1970s and 1980s, to a large extent, provided by venture capital firms in the USA and by the state in Sweden (Edquist, 1993, p12). Whether R\&D is carried out within Universities or in independent public institutes is often, from the viewpoint of industry, irrelevant. Whether the same functions occur within public or private institutions can be also irrelevant from an innovative dynamics perspective.

${ }^{14}$ The Danish case is used by Zysman (1993) to support the hypothesis on national technological trajectories. However, we think that the existing empirical evidence on national trajectories is weak and insufficiently analytic.
} 
technological regimes. Diversity of technologies in the pre-market phase is wider than in the market phase where the market selection process reduces these to several or one dominant design (Cohendet and Llerena, 1995). Linking varieties in different selection environments with forces that structure SI enables a more structured approach to the problem of variety.

Corr 4. Different SI are those where interaction of institutional set-ups and TRs produces a distinctively different techno-institutional configuration (constellation). Varieties in institutional set-ups that do not produce effects in terms of TRs are irrelevant.

\section{Towards conceptualising dynamics of SI}

We have outlined a conceptual model of SI which sheds light on different dimensions of SI and which helps us to structure discussion on SI in more theoretical terms. So far, our discussion has been static, abstracting from the problem of the dynamics or transformation of SI. Here we will only put forward a few ideas on the possible dynamic implications of our framework.

The first element of dynamics in the conceptual model comes from an interplay of pre- and market selection mechanisms. How technology pushed through public funding in the end gets transformed into TR where market selection dominates?

Second, while we recognise that the very notion of SI goes beyond an individual firm it is the firm that is the main agent where transformation of technology into products takes place (Tunzelman, 1995). Pre-market selection mechanisms generated within individual enterprises may change some aspects of TR or even create a new technological regime. Consider IBM who created a TR of the mainframe computer sector or Microsoft who transformed the TR of the PC industry. Individual enterprise may basically redefine the rules of the game and thus reshape SI. On the other hand new organisational regimes, based on flexible specialisation are formed through the interaction of public - private institutions and their development in very local contexts, as the examples of Third Italy, Swiss Jura or German Baden Wurtenberg illustrate.

Third, the co-evolution of TR and institutional set-ups, which is mediated through mechanisms of market and pre-market selection, helps us to understand why 
SI are basically in permanent flux. Robust SI are characterised by the compatibility of TR and the related institutional set-up based on the joint working of pre-market and market selection mechanisms. Fragile or incoherent SI usually suffer from incompatibilities between TR and institutional set-up or the lack of complementarity between market and pre-market selection mechanisms.

\section{Conclusion}

The aim of this paper was to present elements for a more theoretical understanding of SI and not necessarily to come up with a final definition of SI. For such an ill structured issue the definition is less important than its building blocks. Nevertheless, our methodological discussion did generate a definition of SI which reflects the main traits of our conceptual model:

SI is a relatively coherent configuration (constellation) of firms and related institutions and organisations involved in the generation and utilisation of new technologies based on common TR and shaped through mechanisms of market and pre-market selection.

We hope that the developed framework might be used as a piece of appreciative theorising on SI as it enables reference to historical and more empirical types of analysis as well as openining the way for formal or semi formal modelling exercises. 


\section{References:}

Breschi, S. and F. Malerba (1995) Sectoral Innovation Systems: Technological regfimes, Schumpeterian Dynamics and Spatial Boundaries, Paper prepared for the Conference of the 'Systems of Innovation Research network' co-ordinated by C. Edquist, Soderkoping, 7- 10 September 1995

Carlsson, B. and S. Jacobsson (1995) Variety and Technology Policy: How Do Technological Systems Originate, and What Are the Policy Implications, Paper prepared for the Conference of the 'Systems of Innovation Research network' coordinated by C. Edquist, Soderkoping, 7-10 September 1995.

Carlsson, B. and R. Stankiewicz (1987) On the nature, function and composition of technological systems, J. of Evolutionary Economics (1993)1: 93-118.

Cohendet, P. and P. Llerena (1995) Diversity, technical change and public policy: how to valorize diversity, Paper prepared for the Conference of the 'Systems of Innovation Research network' co-ordinated by C. Edquist, Soderkoping, 7- 10 September 1995.

David, P. and D. Foray (1995) Accessing and Expanding the Science and Technology Knowledge Base, STI Review, OECD, Paris, forthcoming

Edquist, Charles (1993) Systems of Innovation - A Conceptual Discussion and Research Agenda, Paper presented at the EUNETIC Network in Strasbourg, March $11-12,1993$

Foray, Dominique (1995) Generation and Distribution of Knowledge, Incentive Structures, Norms and Institutions: The Coherence of a System of Innovation, Paper prepared for the Conference of the 'Systems of Innovation Research network' coordinated by C. Edquist, Soderkoping, 7- 10 September 1995.

Freeman, Chris (1987) Technology Policy and Economic Performance - Lessons from Japan, Pinter Publishers, London.

Freeman, C. and C. Perez (1988) Structural crises of adjustment: business cycles and investment behaviour, In Dosi et al, Technical Change and Economic Theory, Pinter Publishers, London

Humbert, Marc (1994) The Globalisation of Technology as a Challenge for National Innovation Systems, Paper presented at the EAEPE Conference Copenhagen. (not to be quoted)

Lundvall, Bengt-Ake (ed.) (1992) National Systems of Innovation - Towards a Theory of Innovation and Interactive Learning, Pinter Publishers, London

Malerba, F., Orsenigo, L. (1993) Technological Regimes and Firm Behaviour, Industrial and Corporate Change, Vol. 2, No. 1, pp. 45-71. 
Nelson, Richard (ed.) (1993) National Systems of Innovation: A Comparative Study, Oxford University Press.

Niosi, J., P. Saviotti, B. Bellon, M. Crow (1993) National Systems of Innovation: In Search of Workable Concept, Technology in Society, Vol. 15, pp. 207-227.

Patel, P. and K. Pavitt (1994) National innovation systems: why they are important, and how they might be measured and compared, Economics of Innovation and New Technology, vol. 3, pp. 77-95.

Rosenberg, Nathan (1976) Perspectives on Technology, Cambridge University Press

Rosenberg, Nathan (1982) Inside the Black Box: Technology and Economics, Cambridge University Press

Stankiewicz, Rikard (1995) SPRU seminar, April 20.

von Tunzelmann, Nick (1995) Technology and Industrial Progress, Edward Elgar, London

Zysman, John (1993) How Institutions create historically rooted trajectories of growth, BRIE, University of California, October. 